\title{
Acoustic Shielding for a Model Scale Counter-rotation Open Rotor
}

David B. Stephens and Edmane Envia

Glenn Research Center, Cleveland, Ohio 


\section{NASA STI Program . . . in Profile}

Since its founding, NASA has been dedicated to the advancement of aeronautics and space science. The NASA Scientific and Technical Information (STI) program plays a key part in helping NASA maintain this important role.

The NASA STI Program operates under the auspices of the Agency Chief Information Officer. It collects, organizes, provides for archiving, and disseminates NASA's STI. The NASA STI program provides access to the NASA Aeronautics and Space Database and its public interface, the NASA Technical Reports Server, thus providing one of the largest collections of aeronautical and space science STI in the world. Results are published in both non-NASA channels and by NASA in the NASA STI Report Series, which includes the following report types:

- TECHNICAL PUBLICATION. Reports of completed research or a major significant phase of research that present the results of NASA programs and include extensive data or theoretical analysis. Includes compilations of significant scientific and technical data and information deemed to be of continuing reference value. NASA counterpart of peer-reviewed formal professional papers but has less stringent limitations on manuscript length and extent of graphic presentations.

- TECHNICAL MEMORANDUM. Scientific and technical findings that are preliminary or of specialized interest, e.g., quick release reports, working papers, and bibliographies that contain minimal annotation. Does not contain extensive analysis.

- CONTRACTOR REPORT. Scientific and technical findings by NASA-sponsored contractors and grantees.
- CONFERENCE PUBLICATION. Collected papers from scientific and technical conferences, symposia, seminars, or other meetings sponsored or cosponsored by NASA.

- SPECIAL PUBLICATION. Scientific, technical, or historical information from NASA programs, projects, and missions, often concerned with subjects having substantial public interest.

- TECHNICAL TRANSLATION. Englishlanguage translations of foreign scientific and technical material pertinent to NASA's mission.

Specialized services also include creating custom thesauri, building customized databases, organizing and publishing research results.

For more information about the NASA STI program, see the following:

- Access the NASA STI program home page at http://www.sti.nasa.gov

- E-mail your question via the Internet to help@ sti.nasa.gov

- Fax your question to the NASA STI Help Desk at $443-757-5803$

- Telephone the NASA STI Help Desk at 443-757-5802

- Write to: NASA Center for AeroSpace Information (CASI) 7115 Standard Drive Hanover, MD 21076-1320 
NASA/TM-2012-217227

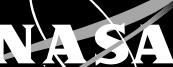

Acoustic Shielding for a Model Scale Counter-rotation Open Rotor

David B. Stephens and Edmane Envia

Glenn Research Center, Cleveland, Ohio

Prepared for the

17th Aeroacoustics Conference

sponsored by the American Institute of Aeronautics and Astronautics and the Confederation of European Aerospace Societies

Portland, Oregon, June 5-8, 2011

National Aeronautics and

Space Administration

Glenn Research Center

Cleveland, Ohio 44135 


\section{Acknowledgments}

This paper was funded by the NASA Environmentally Responsible Aviation project with Dr. Fay Collier as the project manager, and by the NASA Subsonic Fixed Wing project with Dr. Ruben Del Rosario as the project manager. The diffraction shielding calculations were performed using code written by Bruce Walker from Channel Island Acoustics. NASA researchers Dale Van Zante and John Gazzaniga were responsible for managing the open rotor test and the 9 by 15 Wind Tunnel crew assembled and operated the test hardware.

Trade names and trademarks are used in this report for identification only. Their usage does not constitute an official endorsement, either expressed or implied, by the National Aeronautics and Space Administration.

Level of Review: This material has been technically reviewed by technical management.

Available from

NASA Center for Aerospace Information 7115 Standard Drive

Hanover, MD 21076-1320
National Technical Information Service 5301 Shawnee Road Alexandria, VA 22312

Available electronically at http://www.sti.nasa.gov 


\title{
Acoustic Shielding for a Model Scale Counter-rotation Open Rotor
}

\author{
David B. Stephens and Edmane Envia \\ National Aeronautics and Space Administration \\ Glenn Research Center \\ Cleveland, $\mathrm{OH} 44135$
}

\begin{abstract}
The noise shielding benefit of installing an open rotor above a simplified wing or tail is explored experimentally. The test results provide both a benchmark data set for validating shielding prediction tools and an opportunity for a system level evaluation of the noise reduction potential of propulsion noise shielding by an airframe component. A short barrier near the open rotor was found to provide up to $8.5 \mathrm{~dB}$ of attenuation at some directivity angles, with tonal sound particularly well shielded. Predictions from two simple shielding theories were found to overestimate the shielding benefit.
\end{abstract}

\section{Nomenclature}

$f \quad$ Frequency, $\mathrm{Hz}$

$B_{f} \quad$ Number of blades on the front rotor

$B_{a} \quad$ Number of blades on the aft rotor

$N_{f} \quad$ Front rotor shaft rotation frequency, $\mathrm{Hz}$

$N_{a} \quad$ Aft rotor shaft rotation frequency, $\mathrm{Hz}$

$p_{s} \quad$ Complex acoustic pressure when the acoustic shield is in place, $\mathrm{Pa}$

$p_{u} \quad$ Complex acoustic pressure in the unshielded configuration, $\mathrm{Pa}$

$\tilde{p}_{s} \quad$ Measured RMS acoustic pressure spectrum with acoustic shield installed, $\mathrm{Pa}$

$\tilde{p}_{u} \quad$ Measured RMS acoustic pressure spectrum in the unshielded configuration, $\mathrm{Pa}$

SO Propulsor Shaft Order, $2 f /\left(N_{f}+N_{a}\right)$

$\Delta \mathrm{SPL} \quad$ Decibel reduction in sound pressure level due to the acoustic shield

\section{Introduction}

From its inception, the growth in the popularity of jet-powered commercial transportation has been followed by the demand to make such aircraft quieter. A wide variety of aircraft propulsion noise reduction technologies have been explored in the last forty years. Most of the success enjoyed in this endeavor has been due to the adoption of high bypass ratio engines with increasingly large diameter fans. This has reduced both fan noise and jet noise while increasing propulsive efficiency. Further increases in bypass ratio are expected, but a number of technological challenges are making this difficult. These challenges range from the weight of a large fan cowl, to the installation challenges of under-wing mounting, to flutter of large radius fan blades. Additional noise reduction technologies that have seen widespread adoption are acoustic liners for engine nacelles and chevrons to reduce jet exhaust noise. Acoustic shielding is a fundamentally different noise mitigation technique than those mentioned above, in that the noise generated by the engines is not actually reduced, but rather blocked from reaching the observer. In order to meet the aggressive noise reduction goals established by NASA (http://www.aeronautics.nasa.gov/nra_pdf/sfw_proposal_c1.pdf), acoustic shielding of engine noise by the airframe is essential. For example, the difference between the NASA N+1 and $\mathrm{N}+2$ noise goals is assumed to come primarily from switching from conventional to advanced airframes that incorporate shielding. There are many technical challenges to implementing noise shielding by the airframe, including the need for designing an aircraft from ground up to utilize shielding. 
The objective of the present paper is to describe the results from a recent acoustic shielding test that utilized a model scale counter-rotating open rotor as the sound source. The engine simulator provides a realistic representation of what a modern open rotor may sound like, while the shielding geometry in the test was chosen to be simple enough to provide a reference database for noise attenuation theories and code development. Additionally, we have included two simple shielding models to serve as reference prediction capabilities.

As with many topics of applied engineering research, interest in acoustic shielding has waxed and waned over in the last few decades. Early work was mostly analytical and experimental, while recently computational efforts have been brought to bear on the subject. Acoustic shielding predictions for realistic problems are challenging for a number of reasons such as complex airframe geometries, existence of a wide range of length and frequency scales, and complicated source distributions. This combination of issues has resulted in a topic that has a lot of room for development. Below is but a sampling of the body of work dedicated to airframe shielding studies in the last several decades.

In 1975, Conticelli et al. 1] applied a formulation for spherical waves intersecting a semi-infinite plate. They performed a wide range of shielding experiments for both jet and fan noise sources. The location, distribution, and directionality of the sources were found to have a considerable affect on the amount of shielding observed in the far field. For example, they found that while aft radiating fan noise was attenuated considerably, jet noise was not as well attenuated.

Around the same time, a series of studies were carried at NASA Lewis Research Center (now NASA Glenn), concerned with reducing aft engine noise by mounting the engines over a conventional wing, as reported on by von Glahn et al. 2], Reshotko et al. 3] and Bloomer 4. The culmination of the engineover-the-wing research performed by NASA was the Quiet Short-Haul Research Aircraft [5].

Examples of more recent, computationally based work, include Agarwal et al. [6], who proposed a ray-tracing approach based on geometrical optics solutions including diffracted rays. Their work was compared to a validation experiment performed in an anechoic chamber, using a compression driver coupled to a pipe and a two-dimensional profile of the Silent Aircraft geometry. A method, suggested by $\mathrm{Ng}$ and Spakovszky [7], is based on the Kirchhoff diffraction theory. Their implementation considers only the outline of an object and assume only edge diffraction rays. This results in a "medium fidelity" computation that may be a good compromise in predictive quality. An experimental investigation by Czech et al. 8] has been conducted at the Boeing Low Speed Aeroacoustic Facility (LSAF). A planform geometry based on Boeing's Blended Wing Body (BWB) concept has been used along with Jet Noise Rig Simulator to experimentally study shielding effectiveness. The results document up to $20 \mathrm{~dB}$ of noise reduction at some directivity angles. A recent paper by Turkdogru et al. [9] has been specifically concerned with the validity of shielding research performed with simplified sources. The current NASA computational baseline capability is the Fast Scattering Code (FSC) 10] which is a computer-intensive tool.

The present paper describes a recent NASA wind tunnel test that incorporates a model scale open rotor, along with a simplified shielding geometry. The results in this paper are intended to serve as benchmarks for code validation as well as a data set for generating system-level airframe shielding estimates. The next section describes the open rotor shielding experiment and the operating conditions that were run. A section on the experimental results is presented and is followed by a section with predictions from two basic shielding methods that can serve as a benchmark for the more sophisticated codes required to handle realistic, three-dimensional shielding geometries.

\section{Experiment}

A series of acoustic shielding tests was conducted as part of the ongoing wind tunnel testing of a scale model counter-rotating open rotor engine simulator. The open rotor simulator provides scaled aerodynamic performance, structurally responsive blades, and realistic acoustic signatures. In other words, the aeroacoustic, aeroelastic, and performance data from this test rig can be scaled to flight sized engines. Comparisons of model scale acoustic data to the full-scale counter rotating engine flight test in the 1980's were found to be in good agreement. 11]

\subsection{Model Description}

\subsubsection{Drive Rig}

The NASA counter rotating Open Rotor Propulsion Rig (ORPR) was used to power the open rotor blades in this shielding experiment. The rig consists of two counter rotating spools with a non-rotating 
center shaft. Each of the two counter rotating spools is attached to a two-stage air turbine on the aft end that can produce up to $560 \mathrm{~kW}(750 \mathrm{HP})$. The two air turbines are supplied by $2 \mathrm{MPa}(300 \mathrm{psi})$ air heated to $90^{\circ} \mathrm{C}\left(200^{\circ} \mathrm{F}\right)$, and can be independently controlled using a feed-back system to drive the rotor speeds independently up to 8,000 RPM with an accuracy of \pm 15 RPM. This drive rig was last operated in the late 1980's, and was refurbished in order to correct any detrimental effects of long-term storage. The refurbishment activity consisted of a general inspection and rebuild of the mechanical components and construction of a new swept pylon. All instrumentation was inspected and replaced as necessary, including refurbishment of the forward and aft rotating force balances and installation of a telemetry system. The refurbished ORPR installed in the 9x15 Wind Tunnel (described in Section 2.2) is shown in Figure 1 and the microphone instrumentation (described in Section 2.4) is visible in the foreground.

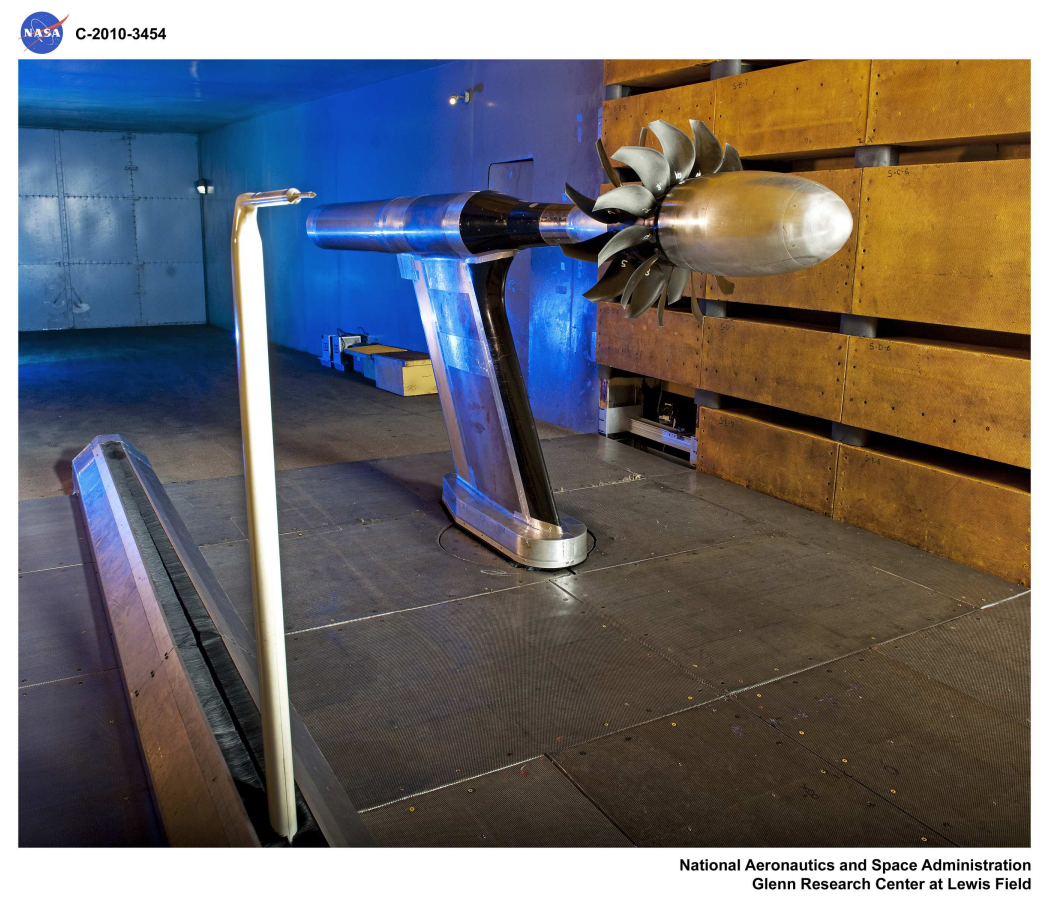

Figure 1: Open Rotor Propulsion Rig in 9x15 Wind Tunnel at NASA Glenn Research Center. NASA Image C-2010-3454.

\subsubsection{Historical Baseline Blades (F31 / A31)}

The model test hardware simulates a counter rotating open rotor unducted fan engine design. New hubs were manufactured as part of the current test campaign, with support for 12 blades for the forward rotor and a 10 blades for the aft rotor. The pitch angle setting for both blade rows are manually adjustable. The blade set used for the data in the present paper was designed and manufactured by General Electric and is known as F31/A31. This blade set represents one of the better early 1990's aerodynamic designs, but is not acoustically optimized. The F31/A31 blade set was manufactured with modern materials and techniques for this test, and will be used to provide a baseline to anchor new data. The forward propulsor is $65.18 \mathrm{~cm}$ (25.66 inches) in diameter with 12 composite fan blades and the aft rotor is $62.97 \mathrm{~cm}(24.79$ inches) in diameter with 10 blades. Axial spacing between the two rotors is variable, but was set at 19.91 $\mathrm{cm}$ (7.84 inches) for this test. The center of the aft rotor at the blade pitch change axis location is the origin of the coordinate system for all results shown in this paper.

\section{$2.29 \times 15$ Wind Tunnel}

The 9x15 Wind Tunnel at Glenn Research Center (GRC) is a low speed wind tunnel with acoustic treatment in the test section. The test section is $2.74 \mathrm{~m}$ high by $4.67 \mathrm{~m}$ wide (9 feet by 15 feet) and $8.72 \mathrm{~m}$ (28.6 feet) long. The test section walls have four $10.2 \mathrm{~cm}$ (4 inch) wide slots that run the length 
of the test section, which are designed to reduce tunnel wall effects. The flow is driven by three electric motors that can produce up to $65 \mathrm{MW}(87,000 \mathrm{HP})$ and drive the tunnel velocity up to Mach 0.22 . A flow conditioner provides a very low turbulence level in the center part of the test section. A description of the 9x15 Wind Tunnel complex is given by Soeder 12. Background noise levels were reported on by Woodward and Dittmar [13] and the acoustic qualities of the facility were documented by Dahl and Woodward [14].

\subsection{Geometry of Shielding Test}

The geometry of the shielding test was a compromise between several objectives. First, the rotor sound source should be unaffected by the presence of the wall. Second, the test should be useful for validation of prediction methods. Third, the results should be useful for estimating the total noise reduction in a system level analysis. The present shielding experiment utilized a simplified barrier geometry that approximates a wing or horizontal stabilizer on a conventional "tube and wing" airframe. A paper by Berton 15. utilizes the measurements from the present test to perform a system level noise study of shielding benefits of a suitable tail on a full sized aircraft.

It should be noted that more complex installations, such as those involving open rotors installed on top of a lifting body were not part of the objective of the present study. Such geometries would introduce additional complexities that would complicate a direct assessment of basic shielding effects. For example, streamlines ingested into the rotor would be distorted by the lifting body, which would change the rotor loading and hence the sound source itself. Additionally, turbulence from the fuselage surface or boundary layer may be ingested into the rotor, which would further complicate the sound producing mechanisms. A consistent rotor sound source was desired, so the barrier wall was located at positions where the flow into the rotor would not be disrupted.

The barrier wall was positioned relative to the open rotor in four different configurations, shown as a sketch in Figure 2. All four were along a $66 \mathrm{~cm}$ (26 inch) sideline distance from the centerline of the model. The barrier wall was $7 \mathrm{~cm}$ (2.75 inches) thick with a 2:1 ellipse on the leading edge and a circular trailing edge. The wall was positioned in two streamwise locations, and both "long" and "short" wall lengths were used. Note that the two "long" configurations were slightly different in length. The forward wall position places the leading edge of the barrier wall slightly upstream of the model forebody. The aft wall position places the nose of the barrier wall even with the center of the aft rotor. A schematic of the two wall location is shown in Figure 2 A table with the relevant geometry details is given in Table 1.

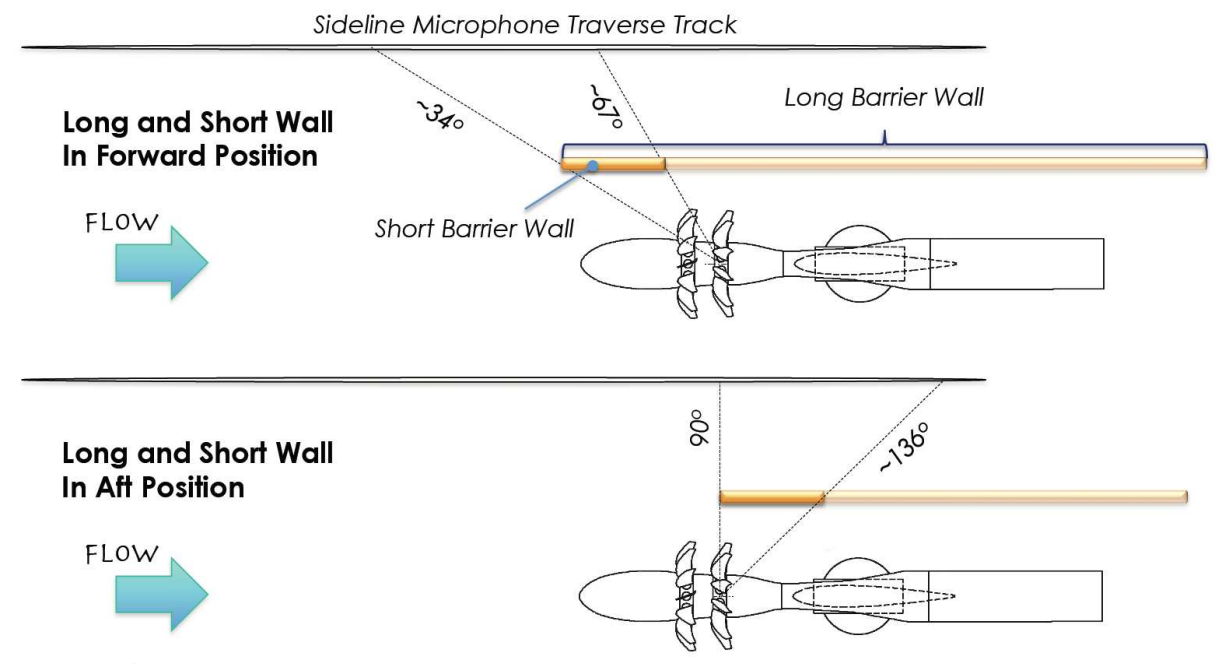

Figure 2: Schematic of Shielding Test.

\subsection{Acoustic Instrumentation}

Acoustic instrumentation was a single Brüel and Kjær $49396.35 \mathrm{~mm}$ (1/4 inch) microphone with the standard bullet nose for making in-flow microphone measurements. This microphone was mounted on 
Table 1: Shielding Configurations

\begin{tabular}{|l|l|l|}
\hline Wall Length & Wall Position & Location of Wall Leading Edge \\
\hline Long $4.42 \mathrm{~m}$ (174 inches) & Forward & $\begin{array}{l}102.4 \mathrm{~cm}(40.3 \text { inches }) \text { Upstream of } \\
\text { Center of Aft Rotor }\end{array}$ \\
\hline Long $3.20 \mathrm{~m}(126$ inches $)$ & Aft & Even with Center of Aft Rotor \\
\hline Short $72.6 \mathrm{~cm}(28.6$ inches $)$ & Forward & $\begin{array}{l}102.4 \mathrm{~cm}(40.3 \text { inches }) \text { Upstream of } \\
\text { Center of Aft Rotor }\end{array}$ \\
\hline Short $72.6 \mathrm{~cm}(28.6$ inches $)$ & Aft & Even with Center of Aft Rotor \\
\hline
\end{tabular}

a linear traverse offset on a $1.52 \mathrm{~m}$ (5 foot) sideline from the centerline of the model. The sideline measurement covers the observation angles between 17.6 and 140 degrees from the upstream axis of the fan, at 18 angles. An RC Electronics DataMAX II data recorder was used to record 15-second samples at $200 \mathrm{kHz}$, along with the once-per-revolution signals from the front and aft rotors. The recorded time series of pressures was processed into sound pressure spectra with $12.2 \mathrm{~Hz}$ frequency bins, using the Digital Acoustics Data System (DADS) codes developed at GRC. In addition, this software applied corrections for the microphone and bullet-nose sensitivity and directivity, and corrected for atmospheric attenuation, resulting in $30.5 \mathrm{~cm}$ (1 foot) lossless pressure spectral densities. Background acoustic levels were documented as part of the model checkout process. The wind tunnel was run with the test rig installed, but without rotor blades, i.e., a tare run. This gives a measure of the background noise level in the wind tunnel including the scrubbing noise caused by airflow over the drive rig. The tare configuration noise was found to be at least $10 \mathrm{~dB}$ lower than the fan data presented in this paper. A muffler was installed on the drive rig exhaust where the airflow through the drive turbines is expelled, and was shown to mitigate noise from the drive rig air turbines. The muffler was used for all measurements presented in this paper. Frequencies below $500 \mathrm{~Hz}$ have been omitted from results shown in this paper, due to background noise in the facility and limitations of the acoustic treatment below $350 \mathrm{~Hz}$.

\subsection{Operating Conditions}

The variable pitch blades were set to nominal take-off pitch angles for this test. The test matrix included two barrier wall locations, two wall lengths, two tunnel Mach numbers, and three rotor RPMs including the rotor at "windmill" condition. The two rotors were driven at equal rotation rates during the powered runs described in this paper. Test parameters are given in Table 2 The complete open rotor diagnostics test matrix includes many more conditions, but the listed subset was deemed adequate for testing acoustic shielding. The operating condition could affect the sound source distribution on the rotor. The diameter of the rotor is roughly the same as the distance between the rotor and the acoustic barrier, and therefore also large with respect to the length of the short barrier. A significant change in the sound source distribution may affect the acoustic shielding, but it is likely a secondary effect compared with the geometry of the system.

The barrier wall measurements with the long wall installed (RDGs 504-529) were compared with the isolated measurements taken the prior day (RDGs 466-496). The short wall measurements (RDGs 1056-1075) were compared against earlier readings (RDGs 4235 and 4241). This is because the blade pitch angles were set slightly improperly for the RDG values 466-529, causing a small shift in the acoustic spectra. Nonetheless, the comparison between the two measurements of attenuation should still be valid.

\section{Results and Discussion}

This section presents selected acoustic measurements from the open rotor with and without shielding. The first section will describe the isolated open rotor, and briefly discuss the character of the radiated sound. The second section will consider the effect of shielding on the sound spectra. An algorithm for quantifying the tone and broadband levels will be presented, and finally the measured attenuation will be reported. 
Table 2: Operating Conditions

\begin{tabular}{|c|c|c|c|c|c|c|c|}
\hline $\begin{array}{c}\text { ESCORT } \\
\text { RDG }\end{array}$ & $\begin{array}{c}\text { Wall } \\
\text { Length }\end{array}$ & $\begin{array}{c}\text { Wall } \\
\text { Location }\end{array}$ & $\begin{array}{c}\text { Tunnel } \\
\text { Mach }\end{array}$ & $\begin{array}{c}\text { Rotor } \\
\text { RPM }\end{array}$ & $\begin{array}{c}\text { Percent } \\
\text { Design } \\
\text { Speed }\end{array}$ & $\begin{array}{c}\text { Corrected } \\
\text { Total Thrust } \\
\text { N (lbf) }\end{array}$ & $\begin{array}{c}\text { Total Shaft } \\
\text { Power } \\
\text { kW (HP) }\end{array}$ \\
\hline 466 & - & - & 0.20 & 5710 & $85.2 \%$ & $1681(378)$ & $179(240)$ \\
470 & - & - & 0.20 & 6486 & $96.7 \%$ & $2535(570)$ & $303(406)$ \\
494 & - & - & 0.22 & 5969 & $88.7 \%$ & $1668(375)$ & $185(248)$ \\
496 & - & - & 0.22 & 6732 & $100 \%$ & $2518(566)$ & $311(417)$ \\
504 & Long & FWD & 0.20 & 5685 & $85.2 \%$ & $1641(369)$ & $176(236)$ \\
506 & Long & FWD & 0.20 & 6461 & $96.7 \%$ & $2495(561)$ & $298(399)$ \\
510 & Long & FWD & 0.22 & 5945 & $88.7 \%$ & $1624(365)$ & $181(243)$ \\
512 & Long & FWD & 0.22 & 6708 & $100 \%$ & $2473(556)$ & $306(410)$ \\
521 & Long & AFT & 0.20 & 5692 & $85.2 \%$ & $1655(372)$ & $177(237)$ \\
523 & Long & AFT & 0.20 & 6468 & $96.7 \%$ & $2522(567)$ & $299(401)$ \\
527 & Long & AFT & 0.22 & 5949 & $88.7 \%$ & $1637(368)$ & $181(243)$ \\
529 & Long & AFT & 0.22 & 6712 & $100 \%$ & $2487(559)$ & $306(410)$ \\
1056 & Short & FWD & 0.20 & 5678 & $85.2 \%$ & $1677(377)$ & $188(252)$ \\
1058 & Short & FWD & 0.20 & 6457 & $96.7 \%$ & $2540(571)$ & $315(423)$ \\
1073 & Short & AFT & 0.20 & 5699 & $85.2 \%$ & $1708(384)$ & $189(254)$ \\
1075 & Short & AFT & 0.20 & 6476 & $96.7 \%$ & $2513(565)$ & $316(424)$ \\
4235 & - & - & 0.20 & 5675 & $85.2 \%$ & $1788(402)$ & $189(253)$ \\
4241 & - & - & 0.20 & 6456 & $96.7 \%$ & $2682(603)$ & $318(427)$ \\
\hline
\end{tabular}

\subsection{Isolated Sound Measurements}

The counter-rotating propellers produce substantial tonal sound with many harmonics. Most of these tones are related to the interaction of the wakes from the forward rotor with the aft rotor blades. Numerous studies have already commented on the sound radiated from counter-rotating propellers ${ }^{(}[16]^{-}[19]^{)}$, but a small sample of results will be presented here.

The present open rotor featured blade counts of 12 on the forward rotor and 10 on the aft rotor. This mismatch results in a large number of "interaction tones." The blade rate tones occur at multiples of 12 and 10 shaft orders, while interaction tones can be approximated as

$$
\text { Shaft Order Interaction Tones }=\frac{m B_{f} N_{f}+n B_{a} N_{a}}{.5\left(N_{f}+N_{a}\right)},
$$

when $m \neq 0$ or $n \neq 0$ and when $N_{f}$ and $N_{a}$ are nearly equal, and shaft order is defined as $\mathrm{SO}=$ $2 f /\left(N_{f}+N_{a}\right)$. For all of the data presented in this paper, the two rotors were set to the same rotation speed, $N_{f}=N_{a}$. In this case, the first few of these tones are shown in Table 3

Table 3: Table of shaft orders for counter rotation propeller tones.

\begin{tabular}{|l|l|l|l|l|l|l|l|}
\hline & $n=0$ & $n=1$ & $n=2$ & $n=3$ & $n=4$ & $n=5$ & $n=6$ \\
\hline$m=0$ & & 10 & 20 & 30 & 40 & 50 & 60 \\
$m=1$ & 12 & 22 & 32 & 42 & 52 & 62 & 72 \\
$m=2$ & 24 & 34 & 44 & 54 & 64 & 74 & 84 \\
$m=3$ & 36 & 46 & 56 & 66 & 76 & 86 & 96 \\
$m=4$ & 48 & 58 & 68 & 78 & 88 & 98 & 108 \\
$m=5$ & 60 & 70 & 80 & 90 & 100 & 110 & 120 \\
\hline
\end{tabular}

A example directivity is shown in Figure 3. The highest tone levels are at shaft orders 42, 32, 34 and 10, respectively. Two very similar frequencies (3460 and $3514 \mathrm{~Hz}$ ) are compared corresponding to $\mathrm{SO}=34.0$ and fractional shaft order 34.5 respectively. The wavelengths of the two frequencies are similar, but their radiated sound directivity is very different. The tone at shaft order 34 exhibits a complicated directivity, while the sound at fractional shaft order 34.5 is effectively broadband, and has a relatively weak dependence on radiation angle. This plot is qualitatively typical of the directivity of specific frequencies. Tones were found to have dense and complicated radiation patterns that were under-resolved by our microphone measurements while broadband noise was a much weaker function of radiation angle. 


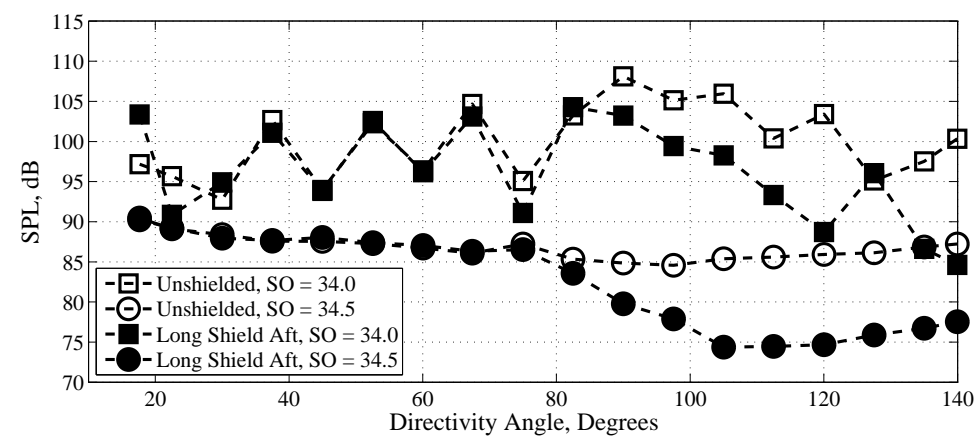

(a) Long barrier wall in aft position

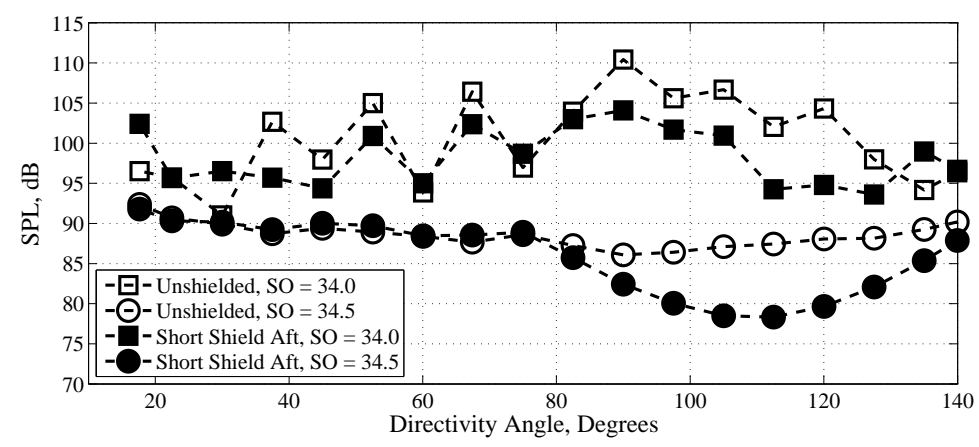

(b) Short wall in aft position

Figure 3: Example directivity of a tone and broadband at nearly the same frequency of $\approx 3500 \mathrm{~Hz} .96 .7 \%$ design speed, $\mathrm{M}=0.20$.

\section{$3.2 \quad$ Effect of Shielding}

The rotor acoustics measured in the shadow region of the barrier wall is significantly different from that for the isolated (i.e., unshielded) rotor. The simplest configuration to consider may be that of the long wall in the aft position. In this case, the upstream edge of the barrier is at the same streamwise location as the aft rotor and the barrier is long enough to be considered semi-infinite in the downstream direction. Measurements from these cases are shown in Figure 4, with a schematic as Figure 4(a). These figures are ordered from forward (no direct shielding) to aft (most shielded region). At $45^{\circ}$ from upstream, shown in Figure 4 (b), the radiated sound is dominated by shaft order tones 22 and 32, followed by 42 and 44 and dozens more tones. The barrier appears to have a small effect on some tones. The subfigures (c), (d) and (e) show the emission angles around $90^{\circ}$, which is the angle tangent to the nose of the barrier wall. When the shield is in place, nearly all the tones are reduced, typically more than $10 \mathrm{~dB}$, which is an order of magnitude or more. This clearly demonstrates the benefits of a large shield blocking the source from the observer. As the observer location moves from behind the barrier wall, the spectra quickly fill with tones and the spectral levels approach the isolated measurement.

The effect of a short wall is shown in Figure 5 for contrast. The short wall has the additional complications of diffraction around both edges of the wall, as well as scattering through the shear layer in the wake of the barrier. A more extensive measurement suite would be required to confirm the effect of the shear layer. Considerable noise reduction was found directly behind the barrier, shown in Figure 5 (e). 


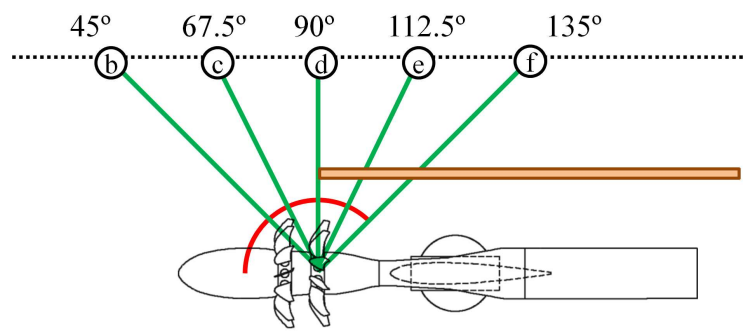

(a) Schematic

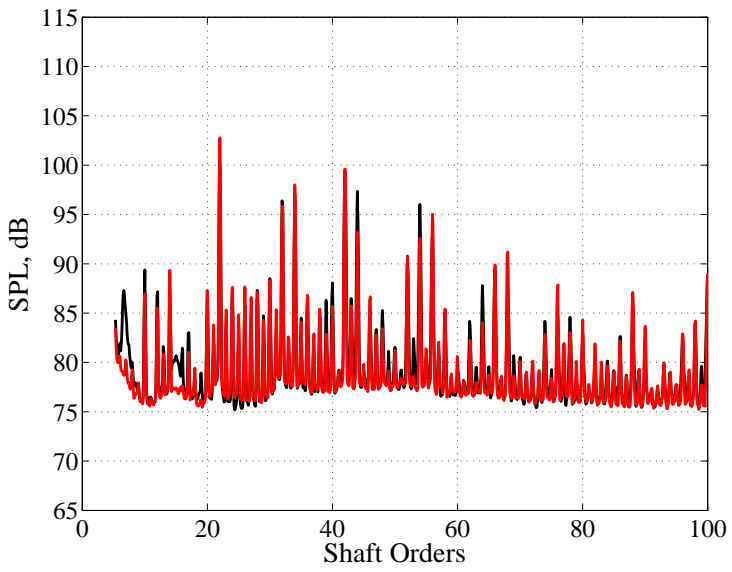

(c) $67.5^{\circ}$

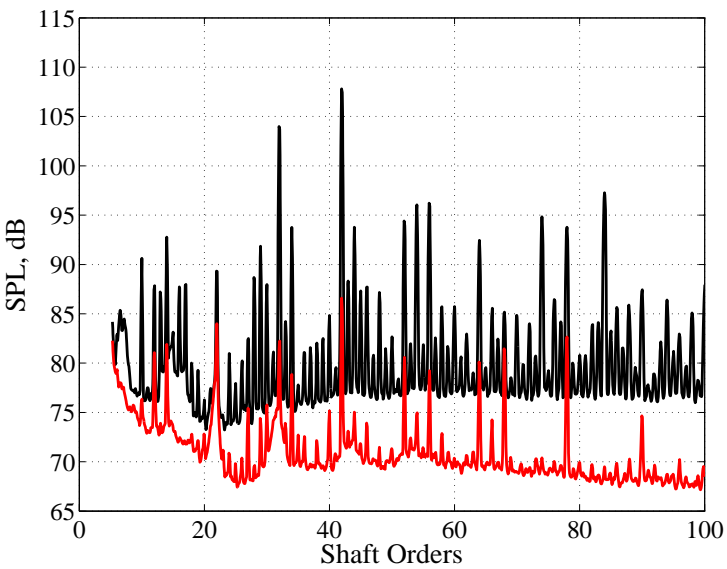

(e) $112.5^{\circ}$

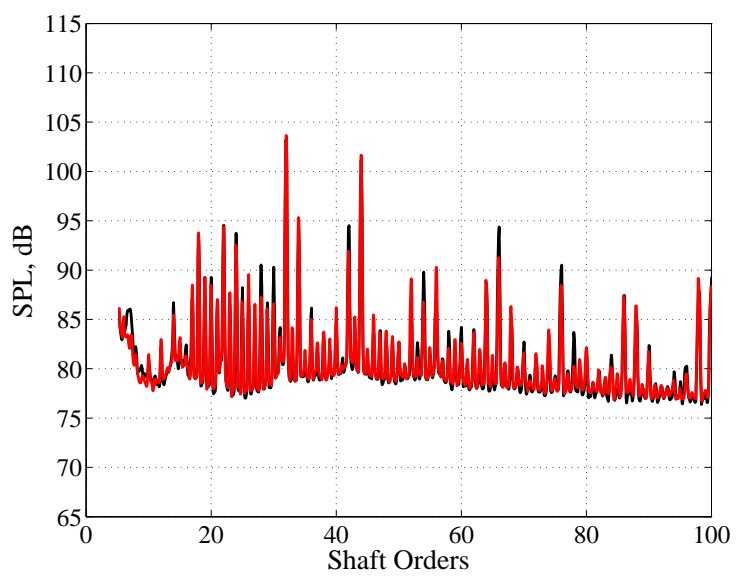

(b) $45^{\circ}$

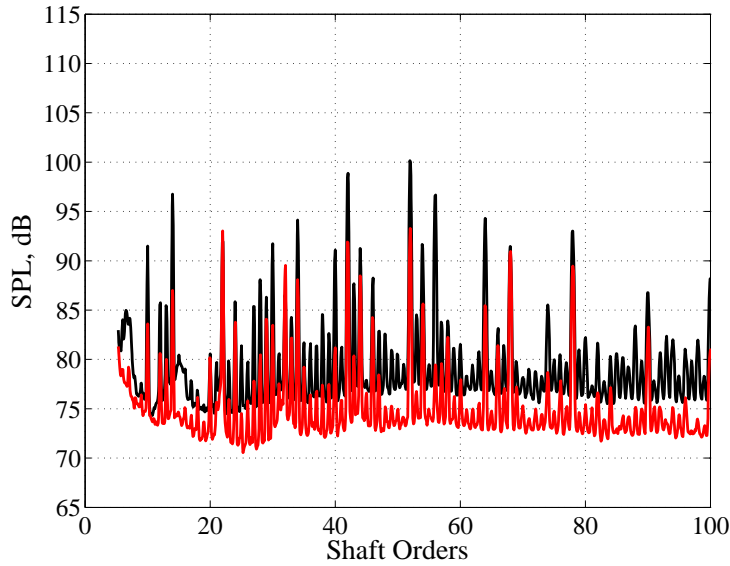

(d) $90^{\circ}$

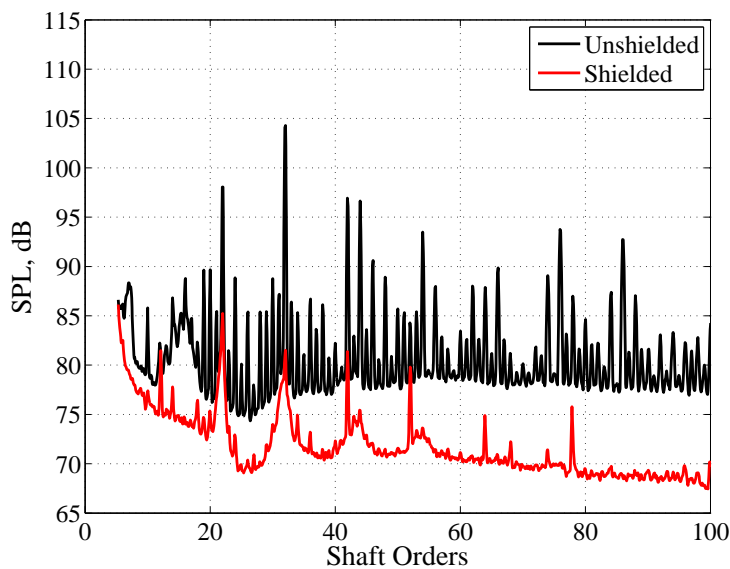

(f) $135^{\circ}$

Figure 4: Comparison of measured sound with long wall aft vs isolated rotor. $85.2 \%$ design speed,, $\mathrm{M}=0.20$. 


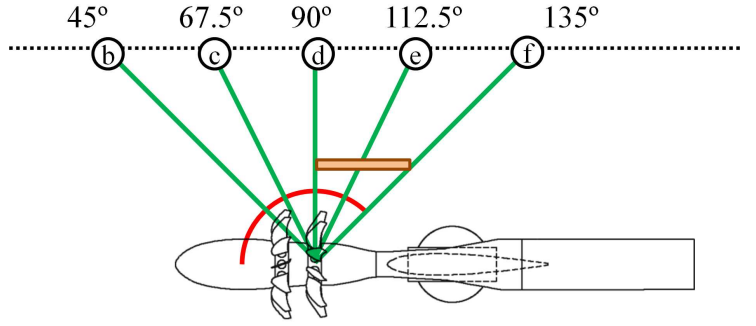

(a) Schematic

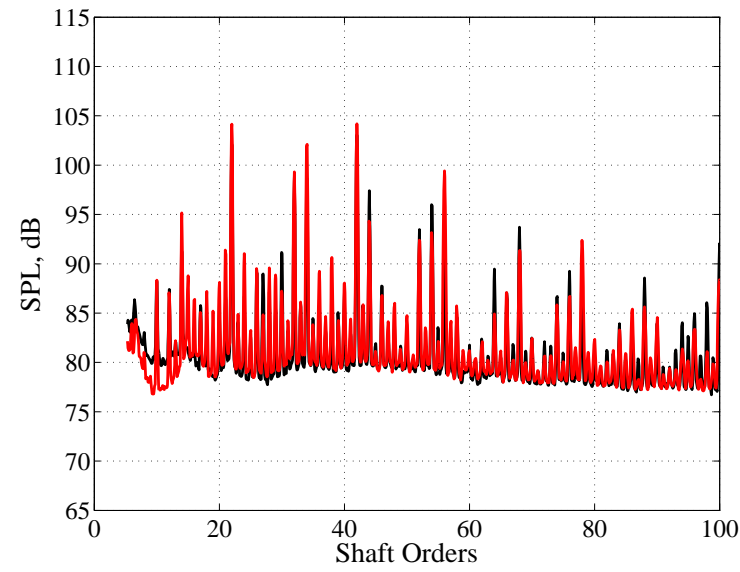

(c) $67.5^{\circ}$

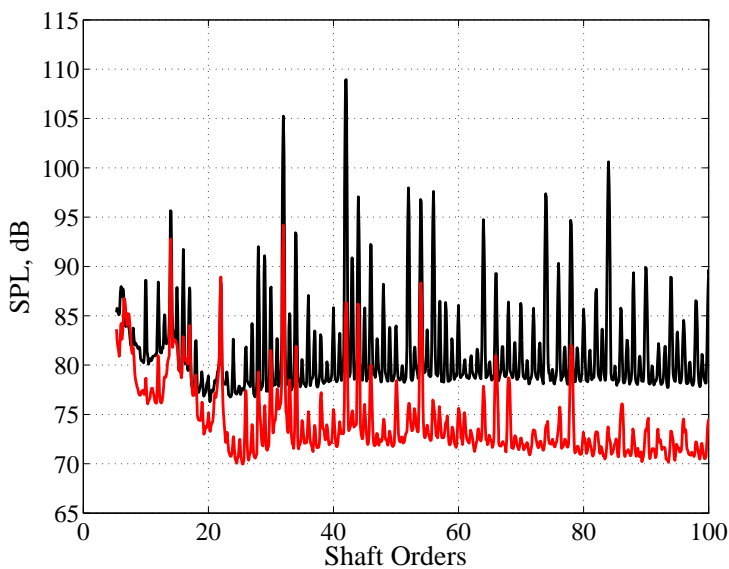

(e) $112.5^{\circ}$

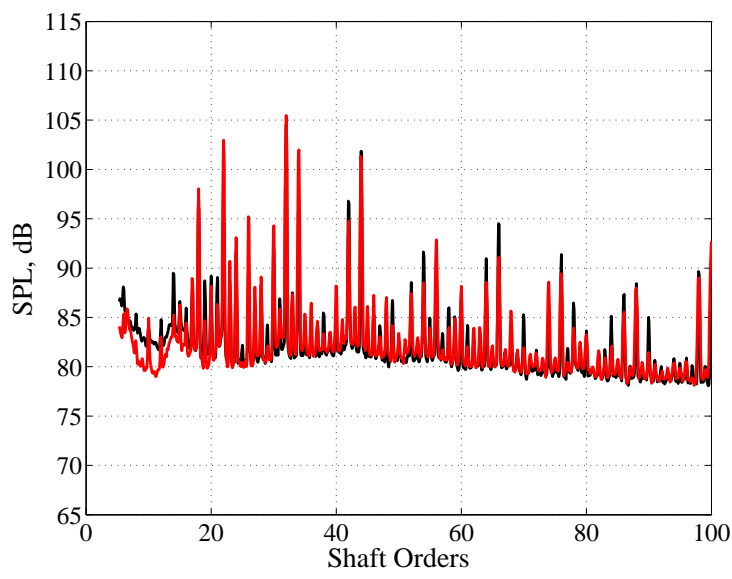

(b) $45^{\circ}$

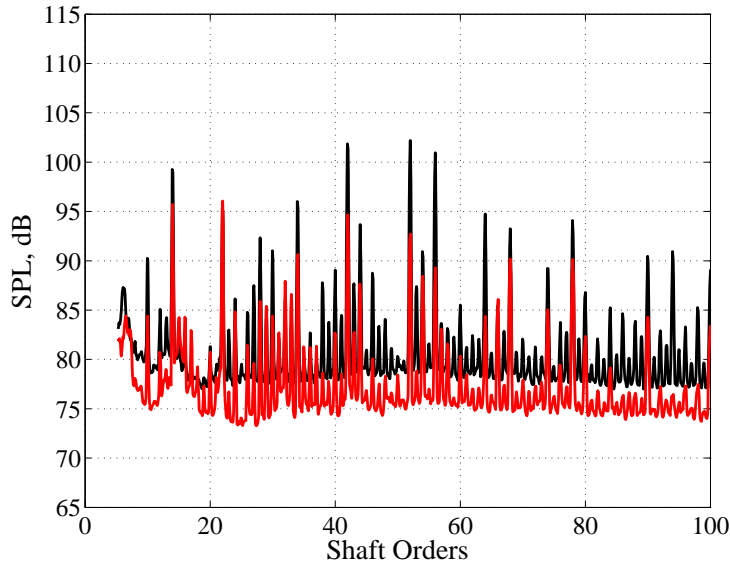

(d) $90^{\circ}$

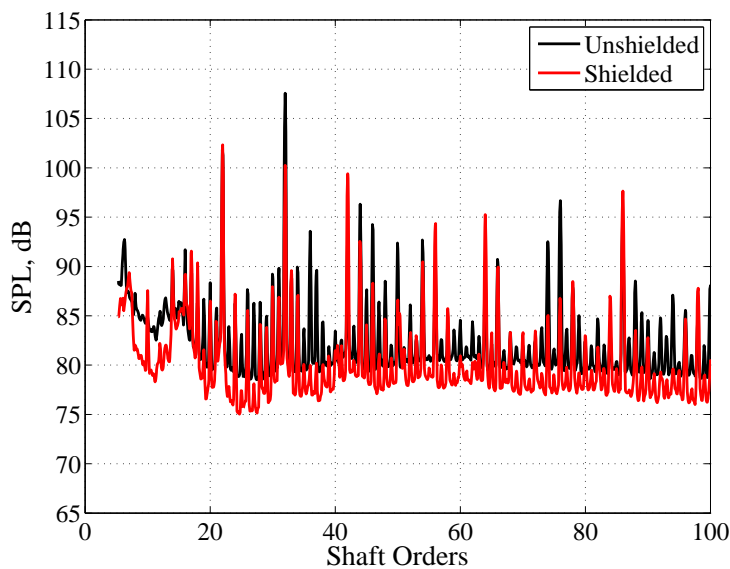

(f) $135^{\circ}$

Figure 5: Comparison of measured sound with short wall aft vs isolated rotor. $85.2 \%$ design speed, $\mathrm{M}=0.20$. 


\subsection{Tone vs Broadband}

A peak-finding algorithm was used to identify the tones in the open rotor sound spectra, defined as levels above broadband of $1 \mathrm{~dB}$ or greater. Each such peak was "chopped off" and replaced with a level that was an interpolated value between the neighboring points. In that way, a reasonably smooth spectrum was created that was devoid of the forest of tones typically observed in open rotor spectra. This curve may be approximately described as the broadband level of the spectrum. This "broadband" spectrum was subtracted (linearly) from the total spectrum to give a spectrum of tones.

Figure 6 shows all three spectra (tone, broadband and total), with tones less than $1 \mathrm{~dB}$ above the broadband hidden. The broadband curves returned by the algorithm were all found to be well-behaved, and relatively weak functions of frequency.

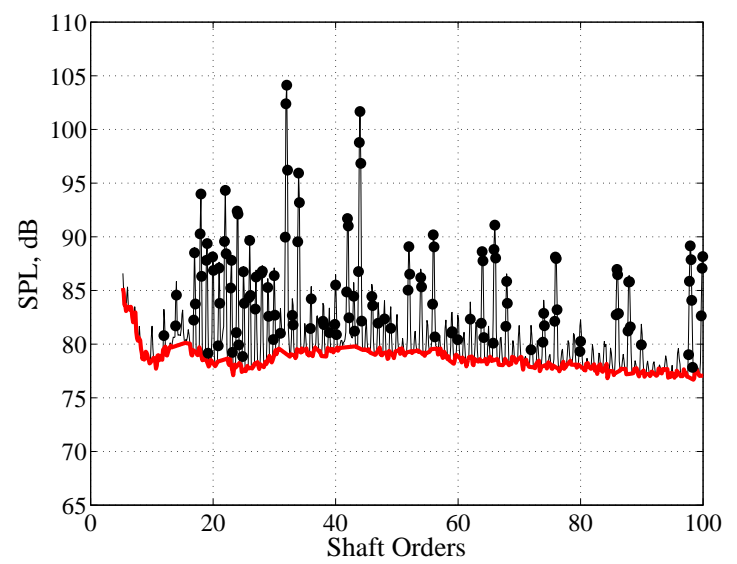

(a) $45^{\circ}$

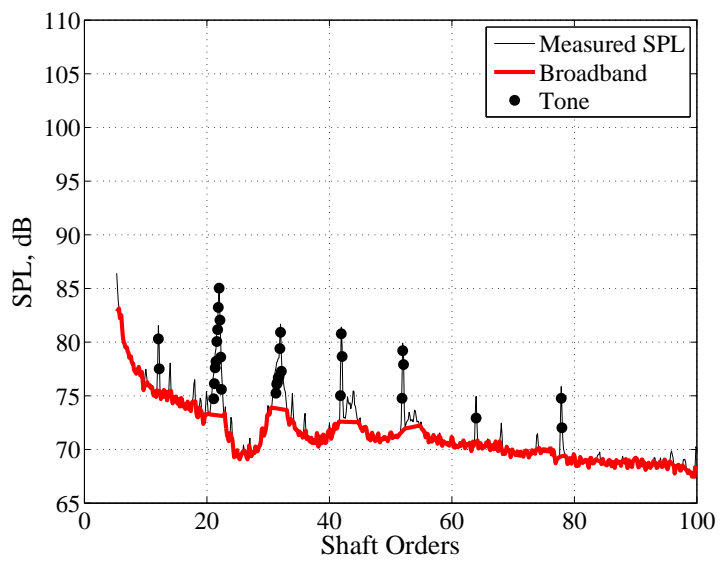

(b) $135^{\circ}$

Figure 6: Tone and broadband separation results for long wall aft, $85.2 \%$ design speed, $\mathrm{M}=0.20$.

\subsubsection{Net Attenuation}

The net attenuation at each angle is defined as the difference between the shielded and unshielded levels after their respective spectrum is integrated over the frequency range from $1 \mathrm{kHz}$ to $50 \mathrm{kHz}$. The tone and broadband spectra as defined in Section 3.3 were integrated at each directivity angle to get an estimate for the tonal and broadband over-all sound pressure level (OASPL). Note that this definition results in OASPL values for tones and broadband that add up to the total OASPL. Simply put:

$$
\text { Attenuation }(\mathrm{dB})=\text { Unhielded OASPL }(\mathrm{dB}) \text { - Shielded OASPL }(\mathrm{dB}) \text {. }
$$

Results from attenuation calculations are shown in Figure 7 For nearly all combinations of wall configuration, operating condition and directivity angles, the tones were found to be attenuated more than the broadband. This is most dramatic when comparing Figure 7 (c) and Figure 7 (d), which feature the exact same geometry, but different operating conditions. The increase in rotor RPM raises the tone level more than the broadband. Consequently, more tones remain above the broadband level at $96.7 \%$ design speed, than do at $85.2 \%$ design speed, when the barrier is introduced.

\section{Shielding Predictions}

For the sake of comparison with these results, predications from two simple acoustic shielding theories were calculated for the shielding geometries investigated here. Neither theory incorporates convective effects of the wind tunnel flow.

\subsection{Barrier Theory}

Standard barrier theory is the type of prediction method usually used for roadside acoustic barriers. The NASA Aircraft Noise Prediction Program (ANOPP) uses this type of method to estimate shielding 


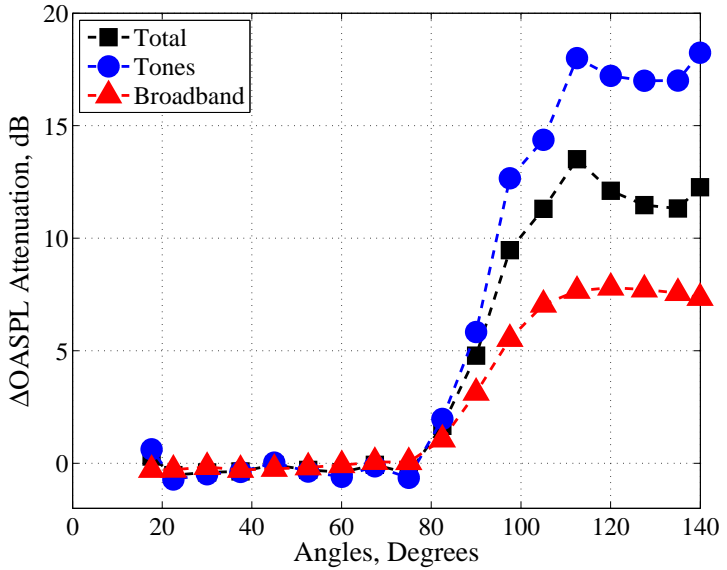

(a) Long wall in aft position, $85.2 \%$ design speed, $\mathrm{M}=0.20$

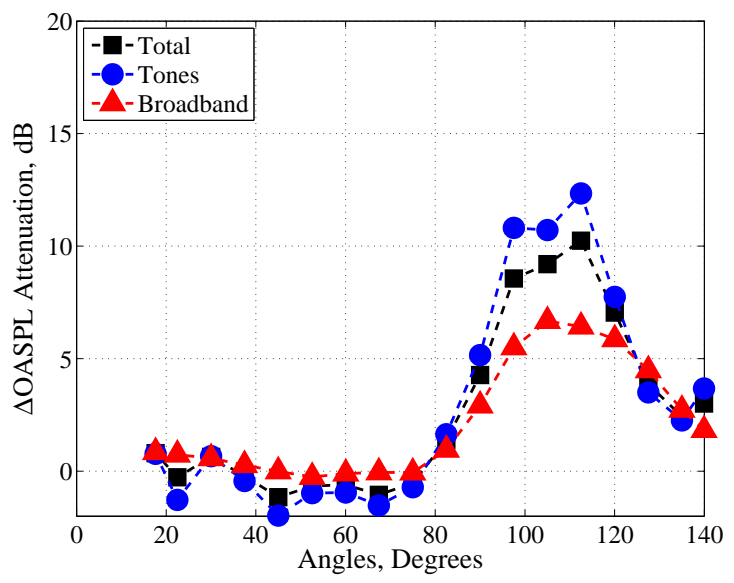

(c) Short wall in aft position, $85.2 \%$ design speed, $\mathrm{M}=0.20$

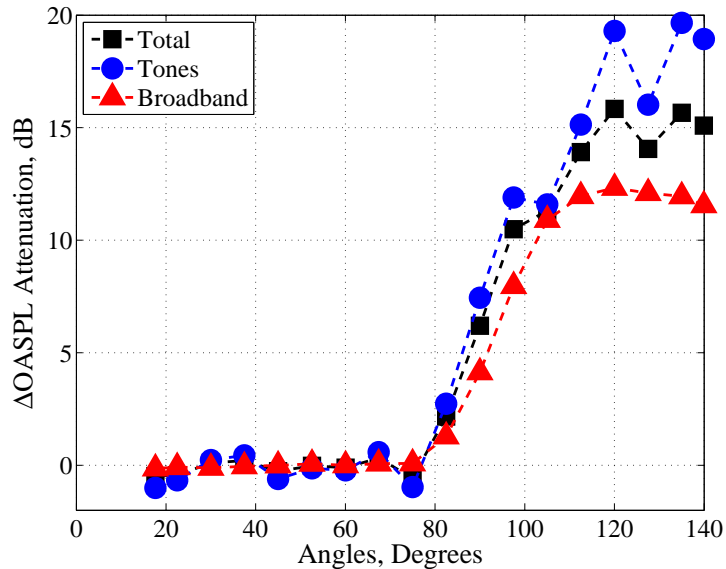

(b) Long wall in aft position $96.7 \%$ design speed, $\mathrm{M}=0.20$

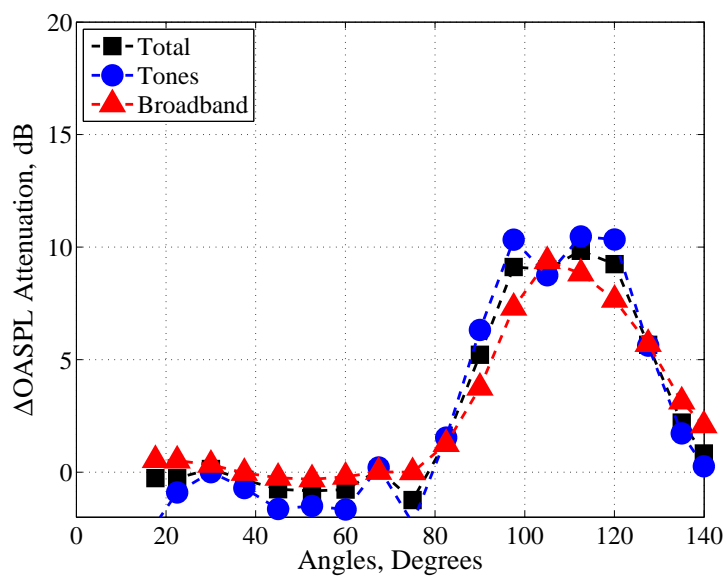

(d) Short wall in aft position, $96.7 \%$ design speed, $M=0.20$

Figure 7: Integrated OASPL results.

effects. Li and Wong 20] provide a review paper that summarizes a number of empirical expressions for barrier theory predictions.

The geometry used for the prediction is shown in Figure 8 The Fresnel number is given as,

$$
N=\frac{k}{\pi}\left(r_{s}+r_{r}-R_{1}\right),
$$

where $r_{s}$ is the distance from the sound source to the edge of the semi-infinite wall, $r_{r}$ is the distance between the edge of the wall and the receiver, $R_{1}$ is the direct distance (in the absence of the barrier) and $k$ is the acoustic wavenumber. It should be noted that, for the purposes of these calculations, the open rotor was taken to be a point source located at the center of the aft rotor.

The Fresnel number was used to calculate the acoustic insertion loss with the empirical expression,

$$
\Delta \mathrm{SPL}=10 \log _{10}(3+20 N),
$$

where the definition of attenuation is the ratio of unshielded sound pressure $p_{u}$ to shielded sound pressure $p_{s}$,

$$
\Delta \mathrm{SPL}=10 \log _{10}\left(\frac{p_{u}}{p_{s}}\right) .
$$

$\mathrm{Li}$ and Wong provide a large number of other empirical expressions that may be slightly more accurate than Eq (4), but all essentially give the same results for the geometry and frequency range presented here. These experimental fits were made to data with Fresnel numbers up to $N=10$, while for the present geometry frequencies of $10 \mathrm{kHz}$ result in some values of Fresnel number over 100, which is a 
significant extrapolation from the curve fit. These high frequencies are not normally associated with roadside barriers. To calculate the attenuation for the short barrier wall, two semi-infinite calculations were carried out, one to account for each end of the barrier. The results were added as

$$
\Delta \mathrm{SPL}=20 \log _{10}\left(\frac{p_{u}}{p_{s_{1}}}+\frac{p_{u}}{p_{s_{1}}}\right),
$$

which assumes the sound passing around each side of the barrier is coherent.

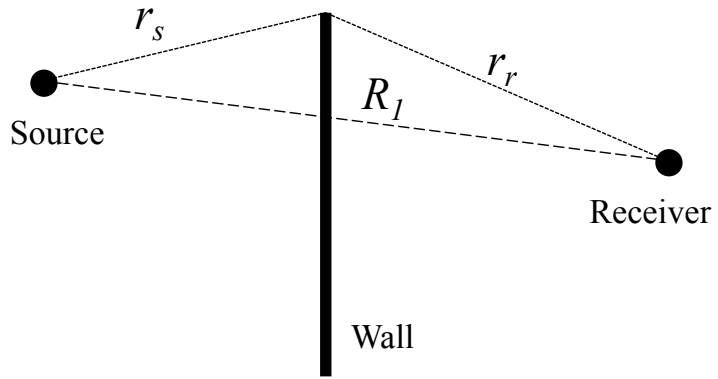

Figure 8: Geometry for barrier wall theory.

The predicted acoustic shielding for the barrier geometry used in the wind tunnel test is shown in Figure 9, where a point at $1 \mathrm{kHz}$ was placed at the location of the aft rotor pitch change axis. The result is essentially a shadow region. For the short wall, the greatest attenuation is immediately behind the barrier.

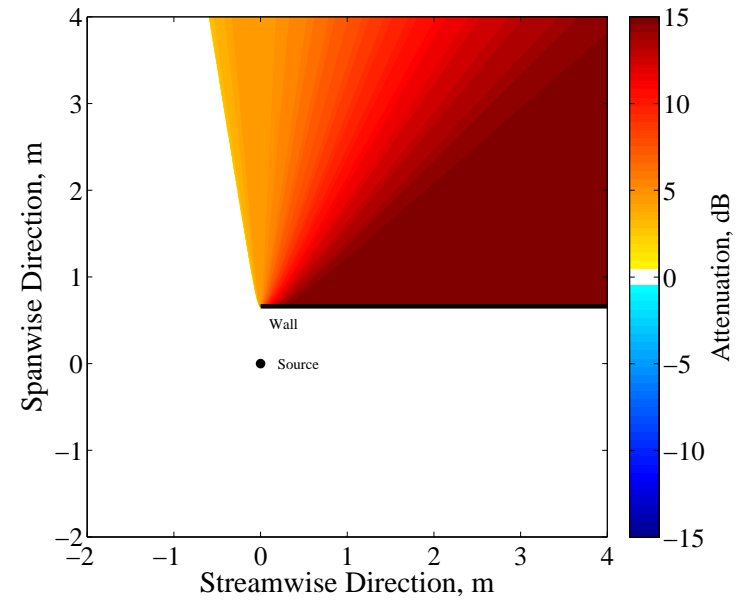

(a) Long Wall Aft.

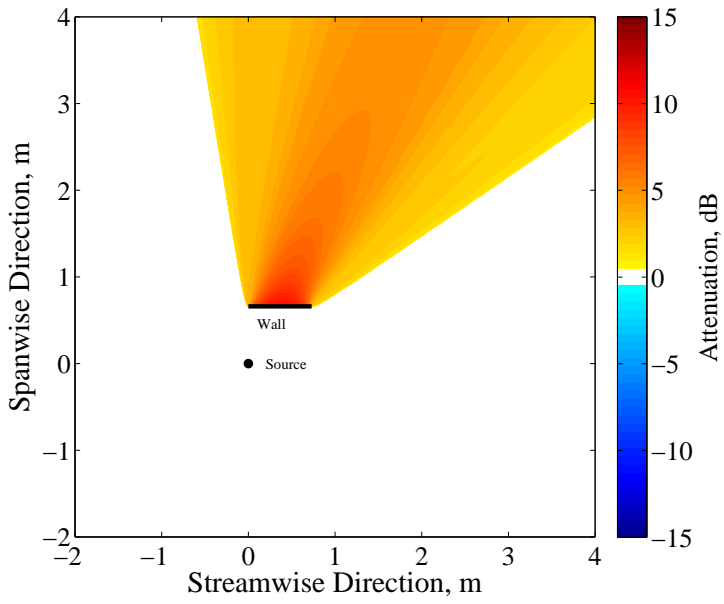

(b) Short Wall Aft.

Figure 9: Barrier theory predictions for acoustic insertion loss at $1 \mathrm{kHz}$.

\subsection{Half-Plane Diffraction Method}

The diffraction of a wave by a finite edge has been presented by Conticelli et al. [1] and Ahtye and McCulley 21, among others. This method requires a Fresnel solution (the corresponding equations will not be reproduced here, for the sake of brevity). The method calculates the complex pressure as a sum of direct and diffracted waves, and offers the potential for solving more sophisticated problems than the barrier theory method. For example, sound due to multiple point sources can be added, possibly simulating one or more propeller disks. Finite edges can be simulated by summing the results from multiple semi-infinite solutions. Good comparisons with carefully performed experiments were demonstrated by Ahtye and McCulley. 
A simulation of geometry for the open rotor shielding experiment was performed. For simplicity, a point source was again used for this result. An adaptation of the method to handle a distribution of sources is currently being developed. Since the rotor diameter, barrier length (for the short wall) and separation distance between the two are all roughly the same, a distribution of sources would be expected to show less total attenuation. The axial separation of the two rotor planes is essentially $1 / 4$ the short barrier length, sound sources would be closer to both edges of the shield, so the attenuation would be less. The distribution of sound sources opens additional complexities that are outside the scope of the present paper, including magnitude, phase and modal content of the distributed source. It is clear that strong tonal content is caused by the rotor-rotor interaction, which will likely have significant implications for shielding of rotor tones. Existing experimental data and propeller noise theories may be tapped to suggest what sort of source distribution would be appropriate to use.

The attenuation at $1 \mathrm{kHz}$ in a two-dimensional plane is shown in Figure 10 for both long and short barriers. In contrast to Figure 9 shown above, the constructive and destructive interference can be easily seen for the short wall case. At $1 \mathrm{kHz}$, the wavelength is roughly $1 / 3$ of the barrier length.

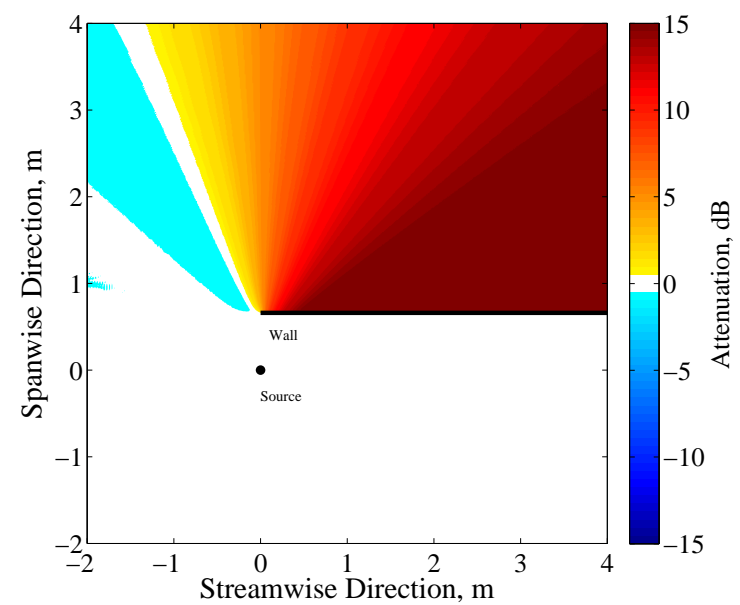

(a) Long Wall Aft.

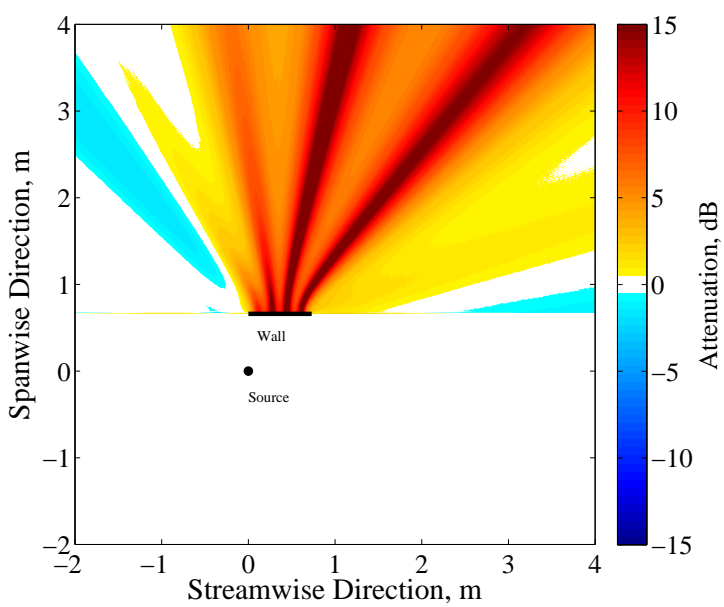

(b) Short Wall Aft.

Figure 10: Diffraction theory predictions for acoustic insertion loss at $1 \mathrm{kHz}$.

\subsection{Comparison with Experimental Results}

The theory presented in this section is for frequency-dependent attenuation along the sideline measured in the wind tunnel. To that end, Figure 11 shows the total attenuation measured by the sideline microphone, as well as the attenuation predicted by barrier theory and diffraction theory. The microphone measurements presented here are in $100 \mathrm{~Hz}$ frequency bins, rather than the $12.2 \mathrm{~Hz}$ bins presented previously. The measurements are made at only 18 sideline locations, so for the sake of simple comparisons, the loss of measurement fidelity is balanced by improved visual comparisons. With the limited spatial resolution in the experiment, however, there is no possibility of measuring the diffraction detail shown in Figure 11 (f).

The results for both predictions and the experiment were averaged over frequency to estimate the total attenuation. This result is shown in Figure 12. For the long wall, both theories agree quite closely, but over predict the attenuation by more than $5 \mathrm{~dB}$ at 130 degrees. For the short wall, both theories again over predict the attenuation, with the diffraction theory result off by over $10 \mathrm{~dB}$ at some angles. The diffraction theory predicts nearly the same result for both walls up to 112.5 degrees, as shown in Table 4 Deficiencies include the point-source approximation and the absence of convection effects. 


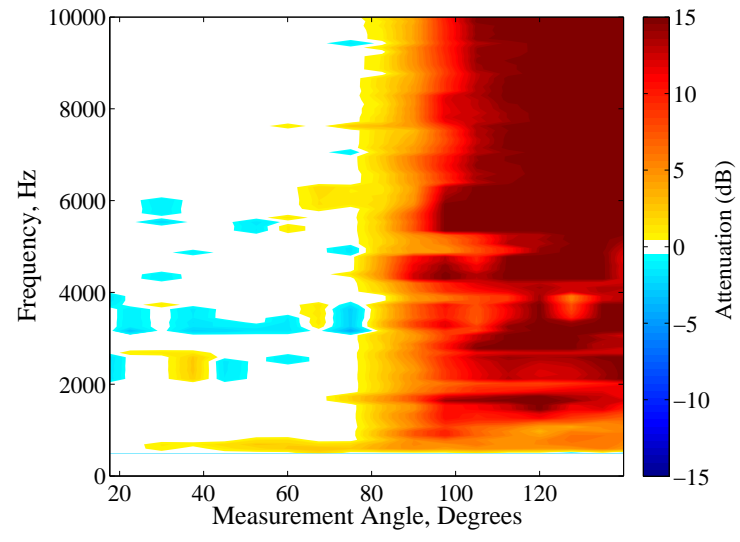

(a) Long wall in aft position.

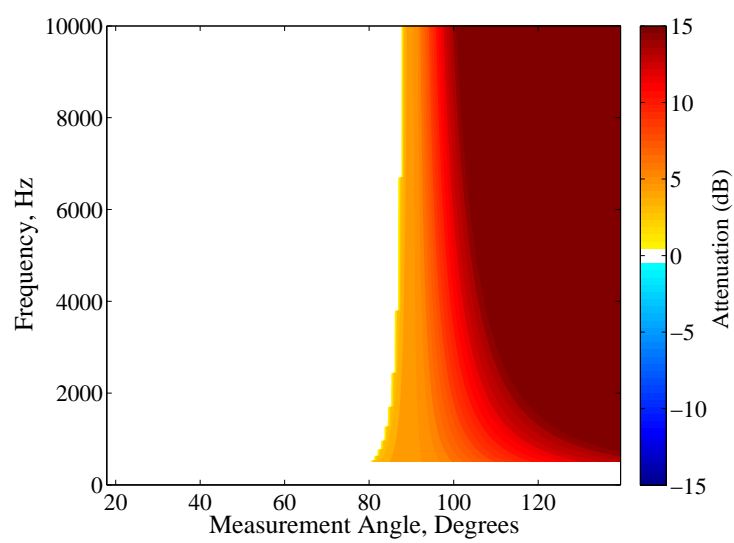

(c) Long wall in aft position.

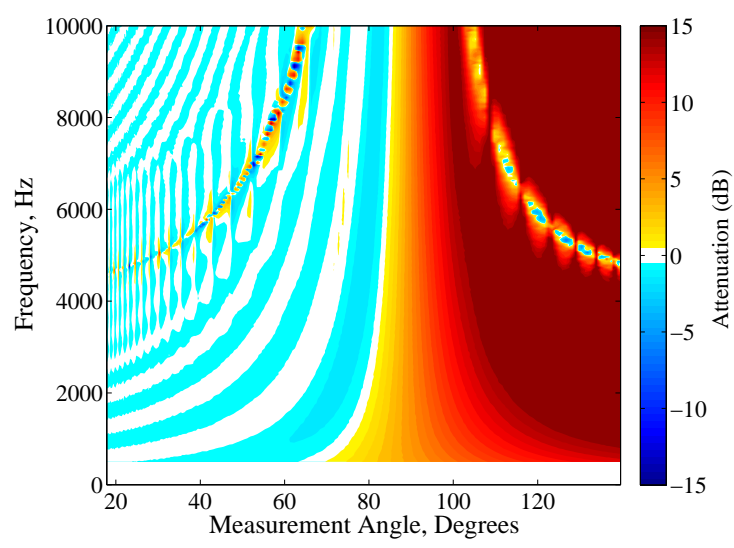

(e) Long wall in aft position.

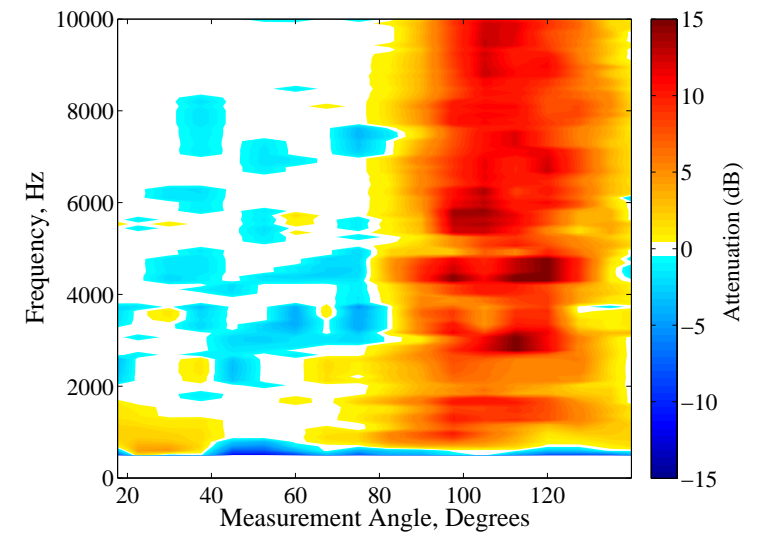

(b) Short wall in aft position.

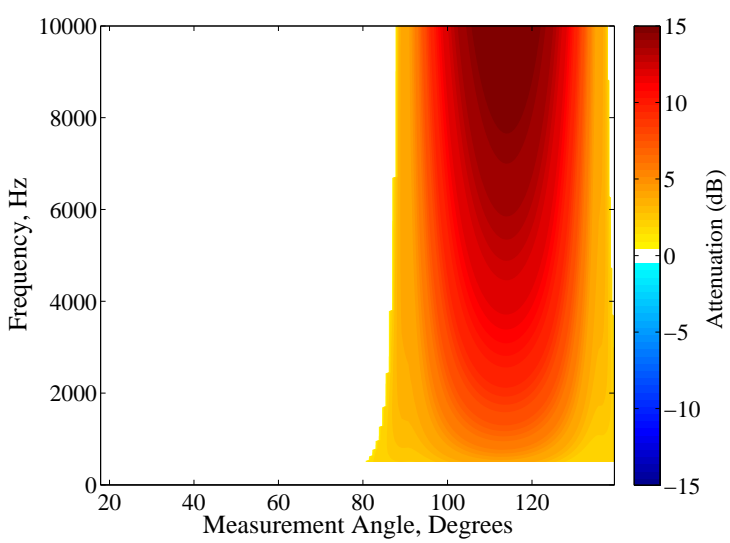

(d) Short wall in aft position.

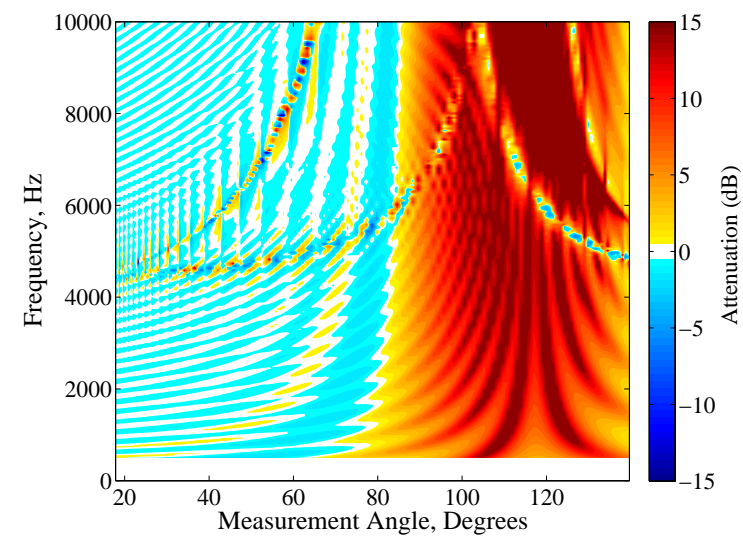

(f) Short wall in aft position.

Figure 11: Frequency dependent barrier wall shielding. (a) \& (b) Measured attenuation, 96.7\% design speed, $M=0.20$. (c) \& (d) Barrier theory predictions for acoustic insertion loss. (e) \& (f) Diffraction theory predictions for insertion loss. 

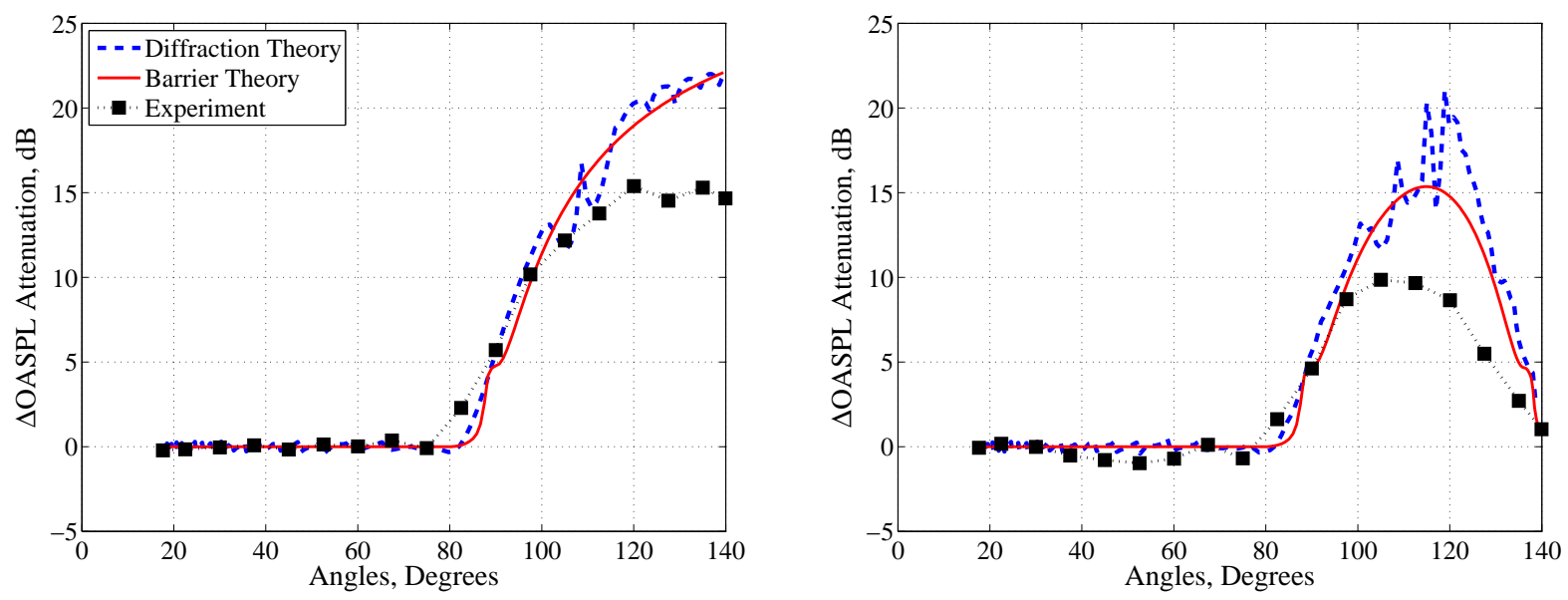

Figure 12: Total frequency-averaged attenuation. a) Long wall in aft position, b) short wall in aft position.

Table 4: Net attenuation at 112.5 degrees.

\begin{tabular}{|c|c|c|}
\hline Method & Long Wall Aft & Short Wall Aft \\
\hline Experiment & $12.6 \mathrm{~dB}$ & $8.7 \mathrm{~dB}$ \\
Barrier Theory & $16.6 \mathrm{~dB}$ & $11.9 \mathrm{~dB}$ \\
Diffraction Theory & $14.9 \mathrm{~dB}$ & $14.1 \mathrm{~dB}$ \\
\hline
\end{tabular}

\section{Conclusions}

An experiment for investigating the fundamentals of acoustic shielding of an open rotor has been reported. The results serve both as a benchmark for evaluating shielding prediction methods as well as providing first order estimates of how much shielding may be expected from wing or tail shielding. The size of the open rotor simulator, the size of the acoustic barrier used in the test, and the distance between the open rotor simulator and the barrier are roughly the same making this an especially challenging case to predict.

Two simple shielding methods were used to provide reference attenuation predictions. The datatheory comparisons indicate that these simple methods do not capture the nuances of shielding behavior and tend to over predict the shielding benefits at high frequencies. It is expected that more advanced prediction methods would result in more accurate predictions. The demonstrated shielding benefits from a simple barrier (such as a wing or tail), together with results from more advanced tests performed elsewhere, strongly suggest the significant potential of shielding of propulsion noise by airframe components, which should keep the interest in this technology high.

\section{References}

[1] Conticelli, V. M., Blasi, A. D., and O'Keefe, J. V., "Noise Shielding Effects for Engine-Over-Wing Installations. AIAA 75-474," 2nd AIAA Aeroacoustics Conference, Hampton, Virginia, USA, March 24-26, 1975.

[2] von Glahn, U., Groesbeck, D., and Reshotko, M., "Geometry Considerations for Jet Noise Shielding with CTOL Engine-Over-the-Wing Concept. AIAA 74-568," 7th AIAA Fluid and Plasma Dynamics Conference, Palo Alto, California, USA, June 17-19, 1974.

[3] Reshotko, M., Goodykoontz, J. H., and Dorsch, R. G., "Engine-Over-the-Wing Noise Research," Journal of Aircraft, Vol. 11, No. 4, 1974, pp. 195-196.

[4] Bloomer, H. E., "Investigation of Wing Shielding Effects on CTOL Engine Noise," 5th AIAA Aeroacoustics Conference, Seattle, Washington, USA, March 12-14, 1979. 
[5] Shovlin, M. D. and Cochrane, J. A., "An Overview of the Quiet Short-Haul Research Aircraft Program," NASA/TM-78545, November 1978.

[6] Agarwal, A., Dowling, A. P., Shin, H.-C., Graham, W., and Sefi, S., "A Ray Tracing Approach to Calculate Acoustic Shielding by the Silent Aircraft Airframe. AIAA 2006-2618," 12th AIAA/CEAS Aeroacoustics Conference, Cambridge, Massachusetts, USA, 8-10 May 2006.

[7] Ng., L. W. T. and Spakovszky, Z. S., "Turbomachinery Noise Shielding Assessment of Advanced Aircraft Configurations. AIAA 2010-3914," 16th AIAA/CEAS Aeroacoustics Conference, Stockholm, Sweden, 7-9 June 2010.

[8] Czech, M. J., Thomas, R. H., and Elkoby, R., "Propulsion Airframe Aeroacoustic Integration Effects for a Hybrid Wing Body Aircraft Configuration. AIAA 2010-3912," 16th AIAA/CEAS Aeroacoustics Conference, Stockholm, Sweden, 7-9 June 2010.

[9] Turkdogru, N., Ahuja, K. K., and Gaeta, R. J., "Validity of the Point Source Assumption in Rotor Noise Measurements with Shielding. AIAA 2010-3853," 16th AIAA/CEAS Aeroacoustics Conference, Stockholm, Sweden, 7-9 June 2010.

[10] Tinetti, A. F., Dunn, M. H., and Pope, D. S., "Fast Scattering Code (FSC) Users Manual, Version 2.0," NASA/CR-2006-214510, October 2006.

[11] Woodward, R. P., Loeffler, I. J., and Dittmar, J. H., "Measured Far-Field Flight Noise of a Counterrotation Turboprop at Cruise Conditions," NASA/TM-101383, January 1989.

[12] Soeder, R. H., "NASA Lewis 9- by 15-Foot Low-Speed Wind Tunnel User Maunal," NASA/TM 106247, August 1993.

[13] Woodward, R. P. and Dittmar, J. H., "Background Noise Levels Measured in the NASA Lewis 9by 15-Foot Low-Speed Wind Tunnel. AIAA 95-0720," 33rd AIAA Aerospace Sciences Meeting and Exhibit, Reno, Nevada, USA, January 9-12, 1995.

[14] Dahl, M. D. and Woodward, R. P., "Comparison Between Design and Installed Acoustic Characteristics of NASA Lewis 9- by 15-Foot Low-Speed Wind Tunnel Acoustic Treatment," NASA/TP-2996, April 1990.

[15] Berton, J. J., "Empennage Noise Shielding Benefits for an Open Rotor Transport," 17th AIAA/CEAS Aeroacoustics Conference, Portland, Oregon, USA, 5-8 June 2011.

[16] Janardan, B. A. and Gliebe, P. R., "Acoustic Characteristics of Counterrotating Fans from Model Scale Tests. AIAA 1989-1142," 12th AIAA Aeroacoustics Conference, San Antonio, Texas, USA, April 10-12, 1989.

[17] Woodward, R. P., "Noise of Two High-Speed Model Counter-Rotation Propellers at Takeoff/Approach Conditions," Journal of Aircraft, Vol. 29, No. 4, 1992, pp. 679-685.

[18] Magliozzi, B., Brown, P., and Parzych, D., "Acoustic Test and Analysis of a Counterrotating PropFan Model," NASA/CR-179590, October 1987.

[19] Elliot, D. M., "Initial Investigation of the Acoustics of a Counter Rotating Open Rotor Model with Historical Baseline Blades in a Low Speed Wind Tunnel," 17th AIAA/CEAS Aeroacoustics Conference, Portland, Oregon, USA, 5-8 June 2011.

[20] Li, K. M. and Wong, H. Y., "A review of commonly used analytical and empirical formulae for predicting sound diffracted by a thin screen," Applied Acoustics, Vol. 66, 2005, pp. 45-76.

[21] Ahtye, W. F. and McCulley, G., "Evaluation of Approximate Methods for the Prediction of Noise Shielding by Airframe Components," NASA TP-1004, January 1980. 


\begin{tabular}{|c|c|c|}
\hline \multicolumn{2}{|c|}{ REPORT DOCUMENTATION PAGE } & $\begin{array}{l}\text { Form Approved } \\
\text { OMB No. 0704-0188 }\end{array}$ \\
\hline \multicolumn{3}{|c|}{ 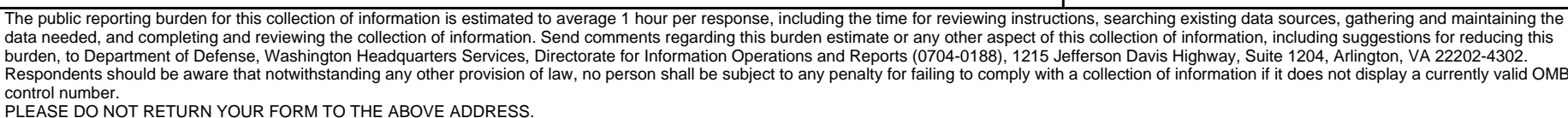 } \\
\hline $\begin{array}{l}\text { 1. REPORT DATE (DD-MM-YYYY) } \\
01-01-2012\end{array}$ & $\begin{array}{l}\text { 2. REPORT TYPE } \\
\text { Technical Memorandum }\end{array}$ & 3. DATES COVERED (From - To) \\
\hline \multirow{3}{*}{\multicolumn{2}{|c|}{$\begin{array}{l}\text { 4. TITLE AND SUBTITLE } \\
\text { Acoustic Shielding for a Model Scale Counter-rotation Open Rotor }\end{array}$}} & 5a. CONTRACT NUMBER \\
\hline & & 5b. GRANT NUMBER \\
\hline & & 5c. PROGRAM ELEMENT NUMBER \\
\hline \multirow{3}{*}{\multicolumn{2}{|c|}{$\begin{array}{l}\text { 6. AUTHOR(S) } \\
\text { Stephens, David, B.; Envia, Edmane }\end{array}$}} & 5d. PROJECT NUMBER \\
\hline & & 5e. TASK NUMBER \\
\hline & & $\begin{array}{l}\text { 5f. WORK UNIT NUMBER } \\
\text { WBS 561581.02.08.03.18.16 }\end{array}$ \\
\hline \multicolumn{2}{|c|}{$\begin{array}{l}\text { 7. PERFORMING ORGANIZATION NAME(S) AND ADDRESS(ES) } \\
\text { National Aeronautics and Space Administration } \\
\text { John H. Glenn Research Center at Lewis Field } \\
\text { Cleveland, Ohio 44135-3191 }\end{array}$} & $\begin{array}{l}\text { 8. PERFORMING ORGANIZATION } \\
\text { REPORT NUMBER } \\
\text { E-17910 }\end{array}$ \\
\hline \multirow{2}{*}{\multicolumn{2}{|c|}{$\begin{array}{l}\text { 9. SPONSORING/MONITORING AGENCY NAME(S) AND ADDRESS(ES) } \\
\text { National Aeronautics and Space Administration } \\
\text { Washington, DC 20546-0001 }\end{array}$}} & $\begin{array}{l}\text { 10. SPONSORING/MONITOR'S } \\
\text { ACRONYM(S) } \\
\text { NASA }\end{array}$ \\
\hline & & $\begin{array}{l}\text { 11. SPONSORING/MONITORING } \\
\text { REPORT NUMBER } \\
\text { NASA/TM-2012-217227 }\end{array}$ \\
\hline \multicolumn{3}{|c|}{$\begin{array}{l}\text { 12. DISTRIBUTIONIAVAILABILITY STATEMENT } \\
\text { Unclassified-Unlimited } \\
\text { Subject Category: } 71 \\
\text { Available electronically at http://www.sti.nasa.gov } \\
\text { This publication is available from the NASA Center for AeroSpace Information, 443-757-5802 }\end{array}$} \\
\hline
\end{tabular}

\section{SUPPLEMENTARY NOTES}

\section{ABSTRACT}

The noise shielding benefit of installing an open rotor above a simplified wing or tail is explored experimentally. The test results provide both a benchmark data set for validating shielding prediction tools and an opportunity for a system level evaluation of the noise reduction potential of propulsion noise shielding by an airframe component. A short barrier near the open rotor was found to provide up to $8.5 \mathrm{~dB}$ of attenuation at some directivity angles, with tonal sound particularly well shielded. Predictions from two simple shielding theories were found to overestimate the shielding benefit.

\section{SUBJECT TERMS}

Acoustics shielding; Open rotor

\begin{tabular}{|c|c|c|c|c|}
\hline \multicolumn{3}{|c|}{ 16. SECURITY CLASSIFICATION OF: } & \multirow{2}{*}{$\begin{array}{l}\text { 17. LIMITATION OF } \\
\text { ABSTRACT } \\
\text { UU }\end{array}$} & \multirow{2}{*}{$\begin{array}{l}\text { 18. NUMBER } \\
\text { OF } \\
\text { PAGES } \\
22\end{array}$} \\
\hline $\begin{array}{l}\text { a. REPORT } \\
\mathrm{U}\end{array}$ & $\begin{array}{l}\text { b. ABSTRACT } \\
\mathrm{U}\end{array}$ & $\begin{array}{l}\text { c. THIS } \\
\text { PAGE } \\
\text { U }\end{array}$ & & \\
\hline
\end{tabular}

19a. NAME OF RESPONSIBLE PERSON STI Help Desk (email:help@sti.nasa.gov) 19b. TELEPHONE NUMBER (include area code) 443-757-5802 

